\title{
ANÁLISE DO POTENCIAL DE IMPLANTAÇÃO DE PROJETOS DE PAGAMENTO POR SERVIÇOS AMBIENTAIS (PSA) NA REGIÃO DE UBERLÂNDIA
}

\author{
M. R. R. ALMEIDAL ${ }^{1}$, R. F. SILVA ${ }^{2}$ E A. C. SANTOS 3 \\ Universidade Federal de Uberlândia \\ mrralmeida@iciag.edu.br ${ }^{1}$; robertofaria1908@hotmail.com ${ }^{2}$; s.c.ale@hotmail.com ${ }^{3}$ \\ Artigo submetido em 07/11/2014 e aceito em 03/05/2019 \\ DOI: $10.15628 /$ holos.2019.2533
}

\section{RESUMO}

Os projetos de Pagamento por Serviços Ambientais (PSA) são uma transação voluntária, onde os proprietários das terras que preservam os recursos naturais como florestas, águas e outros, são compensados financeiramente por agentes públicos ou privados que tenham interesse na preservação destes recursos. Esses projetos conseguem unir a preservação do meio com a geração de renda para os proprietários rurais. O presente estudo apresenta a avaliação do potencial de implantação de projetos de PSA na microrregião de Uberlândia/MG, mais especificamente na cidade de Monte Alegre de Minas. Focou na identificação do tipo de projeto mais adequado para a região, no diagnóstico dos potenciais provedores e no levantamento de potenciais
\end{abstract}

pagadores pelos serviços ambientais. Para este fim, foi aplicado um questionário a 50 proprietários rurais da região para verificar sua disposição e interesse de participar de projetos de PSA e foi realizada uma entrevista semiestruturada com agentes atuantes na área ambiental que poderiam tornar-se pagadores para tais projetos. A partir destes resultados, foi realizada uma análise SWOT. Observou-se um potencial favorável da região para a implantação de um projeto de PSA, devido principalmente ao interesse dos proprietários e da Prefeitura Municipal por projetos desta natureza. Além disso, destacou-se a conservação de recursos hídricos como o tipo de PSA mais adequado para a região.

PALAVRAS-CHAVE: Serviços Ambientais, pagadores, provedores.

\section{ANALYSIS OF POTENTIAL OF PROJECT IMPLEMENTATION OF PAYMENT FOR ENVIRONMENTAL SERVICES (PSE) IN UBERLÂNDIA REGION}

\begin{abstract}
Payment for Environmental Services (PES) projects are a voluntary transaction whereby landowners who preserve natural resources such as forests, water and others are financially compensated by public or private agents that have an interest in preserving these resources. These projects can unite environmental preservation with generation of income for farmers. This study presents an evaluation of the potential deployment of PES projects in the micro region of Uberlândia, Minas Gerais State, Brazil, more specifically in Monte Alegre de Minas town. It focused on identifying the best kind of project for the region, potential providers diagnosis and survey of potential buyers for environmental services. To this end,
\end{abstract}

a questionnaire was given to 50 local farmers to check their interest and willingness to participate in PES projects and a semistructured interview was conducted with active environment agents that could become buying for PES projects. From these results, a SWOT analysis was performed. It was observed a favorable potential of the region for implementation of a PES project, mainly due to the interest of the farmers and the Municipality for such projects. In addition, water conservation was the most suitable type of PES for studied region.

KEYWORDS: Environmental Services, buyers, providers. 


\section{INTRODUÇÃO}

Os ecossistemas naturais proveem uma série de valiosos serviços ambientais, como regulação do clima, formação dos solos, controle contra erosão, armazenamento de carbono, ciclagem de nutrientes, fornecimento de recursos hídricos em quantidade e qualidade, manutenção do ciclo de chuvas, proteção da biodiversidade, elementos culturais, beleza cênica, manutenção de recursos genéticos, entre outros (Guedes \& Seehusen, 2011). Tais serviços, devido a uma deficiente gestão ou a carência de incentivos econômicos para serem preservados, vêm sendo degradados (Pagiola \& Platis, 2003). Assim, torna-se necessária uma nova concepção que reconheça que a utilização dos recursos naturais e ambientais, em maior ou menor grau de intensidade, gera externalidades negativas e a redução no potencial de uso futuro de alguns desses recursos (Kawaichi \& Miranda, 2008).

Inicialmente, a gestão do patrimônio ambiental (provedor de serviços ambientais) baseouse nos princípios do usuário-pagador e do poluidor-pagador: em caso de uso ou dano, respectivamente, acontece o pagamento pelo bem ambiental. No entanto, tem se delineado no cenário de discussões um novo princípio que, segundo alguns autores tem demonstrado ter maior eficácia no controle da poluição (Claassen et al., 2001): é o chamado princípio do protetorrecebedor. A ideia principal deste princípio é que o agente que protege o bem ambiental, sendo um agente público ou privado, em benefício da coletividade deve receber uma compensação financeira como forma de incentivar a proteção dos serviços ambientais (Silva \& Joviano, 2012). Este princípio vai atuar a partir da constatação da insuficiência dos instrumentos de controle como o zoneamento e o licenciamento ambiental, ou seja, ante a insuficiência de instrumentos normativos para a tutela do ambiente, passa-se a utilizar instrumentos econômicos para a efetivação dessa tutela (Hupffer, Weyermüller \& Waclawovsky, 2011). Para Seroa da Motta, Ruitenbeek e Huber (1996), o emprego de instrumentos que oferecem algum incentivo econômico nas políticas ambientais é mais vantajoso em relação aos de comando e controle, já que o "custo social de controle ambiental é menor".

Fundamentado no princípio do protetor-recebedor, surge, então, o instrumento de Pagamento por Serviços Ambientais (PSA), sendo também uma resposta alternativa à crise de escassez de recursos naturais que ganha ênfase no mundo inteiro (Britto, Kato \& Herrera, 2012). A essência de funcionamento dos programas de PSA é que o agente que adotou a conduta ambientalmente positiva deve ser remunerado de alguma forma por meio de algum incentivo fiscal (Hupffer et al., 2011). Existem oportunidades de aplicação do PSA tanto para aumentar a provisão de serviços ambientais em formas de estratégias de conservação e uso de tecnologias e práticas de impacto reduzido como também para recuperar áreas já alteradas, restituindo sua função potencial de provisão de serviços ambientais.

O PSA é um forte instrumento na consecução do desenvolvimento sustentável (Gusmão, 2005), pois, além de um instrumento econômico, constitui-se como mecanismo de política ambiental ao incentivar práticas conservacionistas, sem impedir práticas produtivas (Micol, Andrade \& Borner, 2008). Ainda, o PSA também pode promover a inclusão social (Faganello, 2007) e ser importante na geração de renda dos potenciais provedores de serviços (Zilberman, Lipper \& 
Mccarthy, 2006), trazendo benefícios substanciais para a melhoria da sua qualidade de vida (Landell Mills \& Porras, 2002). Contudo, apesar dos benefícios sociais, é notório destacar que o PSA não pode ser encarado como um mecanismo de redução de pobreza (Pagiola, Arcenas \& Platais, 2005) e a atribuição desse objetivo ao PSA pode comprometer a eficácia em atingir seu objetivo principal (Wunder, Börner, Tito \& Pereira, 2009).

Por todos seus benefícios, o PSA tem sido utilizado por várias instituições e governos ao redor do mundo como forma de melhoria da gestão do patrimônio ambiental, sendo a Costa Rica um dos primeiros países a implementar o PSA, no caso, para conservação de florestas.

No contexto brasileiro, o PSA tem sido uma ferramenta efetiva adotada por distintas regiões, fruto da atuação conjunta entre a sociedade civil e o Poder Público que tem demonstrado meios eficazes de preservação dos ecossistemas do país (Jodas, 2010). Apesar de ainda haver muitos desafios de ordem técnica e financeira, bem como institucional e legal para que o PSA (Guedes \& Seehusen, 2011), existem diversas iniciativas de implementação, entre as quais, podese citar o Programa de Desenvolvimento Socioambiental da Produção Familiar Rural (Proambiente) que realizou experiências pioneiras, mas ainda incipientes, com compensações comunitárias pela prestação de um conjunto de serviços ambientais para pequenos produtores na Amazônia (Wunder et al., 2009); e o Programa Conservador das Águas, implantado pela prefeitura da cidade de Extrema/MG, em parceria com a The Nature Conservancy (TNC), sendo a primeira iniciativa municipal brasileira desse gênero (Ribeiro, Chaves, Jacovine \& Silva, 2007).

Em Minas Gerais, foi criado por meio da Lei Estadual no 17.727/2008 e normalizado pelo Decreto Estadual no 45.113/2009, o Programa Bolsa Verde que concede incentivo financeiro a proprietários e posseiros rurais para identificação, recuperação, preservação e conservação de áreas necessárias à proteção das formações ciliares e à recarga de aquíferos e áreas necessárias à proteção da biodiversidade e ecossistemas especialmente sensíveis (Minas Gerais, 2008). Alguns proprietários da região de Uberlândia já estão sendo beneficiados por este programa. Contudo, conforme apontado pelo Instituto Estadual de Florestas (IEF, 2010), os recursos atualmente alocados no Programa tendem a ser insuficientes para atender a toda demanda prevista.

Como, a maioria de esquemas pioneiros de PSA é estabelecida em âmbito local (Wunder et al., 2009; Jodas, 2010), o presente trabalho objetivou avaliar o potencial da microrregião de Uberlândia para a criação de outros projetos de Pagamentos por Serviços Ambientais, por meio de um diagnóstico dos potenciais provedores e do levantamento de potenciais pagadores pelos serviços ambientais, além de identificar o tipo de projeto mais adequado para a região. Para este fim, foi escolhida a cidade de Monte Alegre de Minas por ser um município de pequeno porte, que tem na agricultura sua maior contribuição para o Produto Interno Bruto (PIB).

\section{REVISÃO BIBLIOGRÁFICA}

\subsection{Conceitos}

São considerados serviços ambientais aqueles desempenhados pelo meio ambiente que resultam em condições adequadas à sadia qualidade de vida (Câmara dos Deputados, 2009). Esses serviços podem ser classificados em quatro conjuntos principais: provisão (alimentos, água potável, madeiras e fibras), regulação (clima, doenças e ciclo da água) suporte (ciclagem de 
nutrientes, formação do solo) e cultural (estético, espiritual, educativo e recreativo) (Millenium Ecosystem Assessment, 2005).

Embora não possuam um preço pré-definido, os serviços ambientais são extremamente valiosos e caros (Bensusan, 2002). É possível atribuir-lhes diferentes valores: o valor de uso direto deriva do uso direto da exploração dos recursos naturais, enquanto que o valor de uso indireto engloba as funções ecossistêmicas, como proteção da bacia hidrográfica, ciclagem de nutrientes, manutenção da biodiversidade, entre outros; o valor de opção decorre da opção de usar direta ou indiretamente o recurso natural no futuro; e o valor de existência advém de questões morais, culturais, éticas ou altruístas, ou seja, é o valor que as pessoas atribuem aos recursos ambientais sem que estejam ligados a alguns de seus usos (Seroa da Mota, 1998).

Somente o valor de uso direto é fácil de ser tratado economicamente; contudo, este tipo de uso tem grande potencial para gerar degradação ambiental e comprometer a prestação dos serviços ambientais que não sejam de provisão. Diante disto e da importância e necessidade de manutenção destes serviços, foi criado um conjunto de mecanismos, denominado PSA, que tem como principal objetivo manter os ativos e serviços oferecidos pela natureza, por meio da recompensa ou remuneração para aqueles que os preservam (Moraes, 2012). Assim, PSA é a retribuição, monetária ou não, às atividades humanas de restabelecimento, recuperação, manutenção e melhoria dos ecossistemas que geram serviços ambientais e que estejam amparadas por planos e programas específicos (Câmara dos Deputados, 2009). Ainda, os PSA podem ser considerados esquemas flexíveis, mecanismos diretos e promissores de compensação (Forum Regional, 2004), que tem como principal objetivo manter os serviços oferecidos pela natureza, por meio da recompensa/remuneração para aqueles que os preservam (Moraes, 2012).

Wunder et al. (2009) detalham mais o conceito, definindo PSA como: uma transação voluntária, na qual um serviço ambiental bem definido ou um uso da terra que possa assegurar este serviço é comprado por, pelo menos, um comprador de, pelo menos, um provedor sob a condição de que o provedor garanta a provisão do serviço. Assim, geralmente, estão presentes neste fluxo três atores sociais básicos: os provedores que recebem a compensação financeira; os recebedores que pagam pelos serviços; e os mediadores (interlocutores) que são órgãos governamentais ou não, atuantes na relação entre provedor-recebedor (Moraes, 2012).

\subsection{Condições e componentes para a implementação de um PSA}

Não há uma receita única para se conceber um sistema de PSA e sempre é preciso adaptar a estratégia de intervenção às realidades locais (Ministerio del Ambiente [MINAM], 2010). Contundo, alguns autores apontam para condições e componentes que um programa de PSA deve obedecer. Santos, Brito, Maschietto, Osório e Monzoni (2012) focam em nove componentes considerados essenciais no que diz respeito a regime jurídico robusto de PSA: arranjo institucional; tipos de serviços ambientais abrangidos; fontes de recursos; beneficiários; categorias fundiárias elegíveis para os programas; requisitos de acesso ao recebimento de benefício; remuneração e critério de cálculo; sistemas de verificação de prestação do serviço; e salvaguardas socioambientais. Para Wunder et al. (2009), existem uma série de condições necessárias para a implementação de um sistema de PSA: precondição econômica e competitiva (existência de disposição para o pagamento de um valor ao provedor de serviços ambientais por uma externalidade - benefício); precondição cultural (aceitação e motivação do provedor em fornecer 
serviços ambientais mediante incentivos econômicos); precondição institucional (condição de confiança mínima entre usuários e provedores de serviços, apontando para uma expectativa de cumprimento mútuo de contrato, associada a uma infraestrutura institucional capaz de administrar a transferência condicional do PSA de forma eficiente e transparente); e precondições informacionais (necessidade de definição e mensuração dos serviços ambientais pelos quais os provedores seriam compensados, bem como monitoramento de sua provisão e negociação de contratos).

Considerando as fases de desenvolvimento de PSA, MINAM (2010) divide este processo em três fases: diagnóstico, desenho e implementação. A fase de diagnóstico (etapa inicial para a proposição de um PSA) é dividida em três passos. O primeiro envolve a caracterização do ecossistema, a identificação dos serviços ambientais e a definição do problema ambiental. 0 seguinte trata da análise dos atores envolvidos (compradores e provedores de serviços ambientais) e do contexto econômico da região. Depois, no terceiro passo, é preciso identificar as alternativas de manejo, valoração econômica e instrumentos financeiros.

Por fim, King, Letsaolo e Rapholo (2003) destacam alguns passos e condições básicos que devem ser tomados para a implantação e funcionamento de um PSA: definir de forma clara quais os serviços ecossistêmicos que devem ser fornecidos pelo instrumento elaborado; estabelecer que um serviço é benéfico e determinar quais as práticas que o fornecem; verificar a existência de uma disposição a pagar pelo benefício gerado; projetar e implantar o sistema de pagamentos e instituições de apoio; estruturar um sistema de monitoramento para verificar a eficiência social, econômica e ambiental do PSA; os direitos de propriedade devem ser bem definidos para se poder ter uma definição precisa de quem está oferecendo e quem está recebendo os serviços; os bens e serviços devem ser "precificados" corretamente para que não ocorram falhas na alocação dos recursos; e os custos de participação e de transação devem ser os mais baixos possíveis para permitir o acesso do maior número de participantes e para dar viabilidade econômica ao processo.

Resumindo estas informações, na Figura 1 são apresentados os fatores que devem ser considerados em um PSA. Eles envolvem base legal do instrumento, identificação do serviço a ser remunerado, do provedor e do comprador deste serviço e a forma como a negociação será feita. 


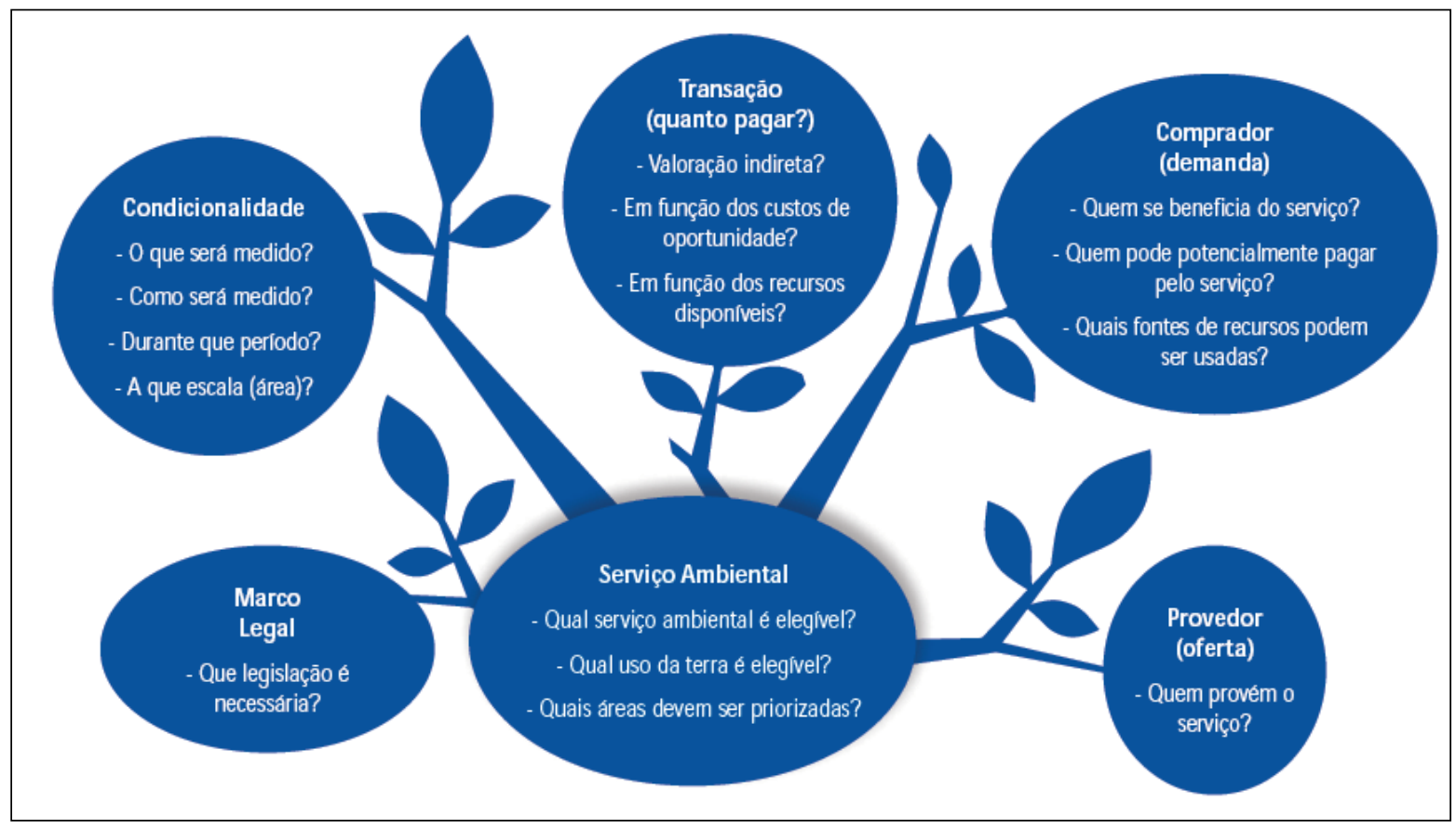

Figura 1: O que uma proposta de PSA deve considerar. Fonte: Guedes e Seehusen (2011)

\subsection{Tipos e iniciativas de PSA}

Apesar da variedade de programas, Wunder et al. (2009) afirmam que quase todos os PSA existentes compreendem serviços ambientais associados a uma das quatro categorias distintas:

- retenção ou captação de carbono: exemplos desta categoria são a captura de carbono por vegetação em crescimento ou a condição de retenção de carbono no solo e na vegetação. 0 benefício pelo qual se paga seria o efeito potencial de mitigação das mudanças climáticas causadas por emissões antropogênicas.

- conservação da biodiversidade: inclui a regulação e estrutura do ecossistema, diversidade genética e de espécies, sendo remunerado o valor de opção (uso futuro) e o valor de existência (conhecimento da existência e importância).

- conservação de serviços hídricos: abrange ações de purificação da água, regulação de fluxo e sedimentação, onde se paga pela qualidade e quantidade de água. Young (2005) destaca que PSA vem se tornando uma ferramenta interessante em iniciativas de controle da erosão e da sedimentação em pequenas bacias hidrográficas rurais.

- conservação de beleza cênica: aplicado a paisagens naturais e, em alguns casos, a patrimônios culturais. Paga-se pela recreação e opções para turismo.

Existem diversas iniciativas de PSA implantadas e em implantação no mundo. A Costa Rica é o país mais adiantado da América Latina em termos de políticas públicas para proteção ambiental e uso de mecanismos de PSA voltados para o manejo de bacias hidrográficas. Porém, outros países como a Nicarágua, Honduras, Equador e Brasil também têm avançado em experiências relacionadas a esse tema (Bernardes \& Junior, 2010). Alguns exemplos são apresentados na Tabela 1.

Tabela 1: Iniciativas de PSA pelo mundo. Fonte: adaptado de Wunder et al. (2009). 


\begin{tabular}{|c|c|c|c|}
\hline Esquema & País(es) & Serviço(s) & Pagamentos por \\
\hline Profator & Equador & Carbono & Restauração (plantação) \\
\hline Pimampiro & Equador & Água & Conservação/Recuperação \\
\hline Risemp & $\begin{array}{l}\text { Colômbia } \\
\text { Costa Rica } \\
\text { Nicarágua }\end{array}$ & $\begin{array}{l}\text { Biodiversidade e } \\
\text { carbono }\end{array}$ & Recuperação (Silvipastoril) \\
\hline $\begin{array}{c}\text { Conservation Reserve } \\
\text { Program (CRP) }\end{array}$ & USA & $\begin{array}{l}\text { Água, biodiversidade, } \\
\text { solo, etc. }\end{array}$ & $\begin{array}{c}\text { Recuperação (práticas } \\
\text { agrícolas e retirada de terras } \\
\text { da produção) }\end{array}$ \\
\hline PSA program & Costa Rica & $\begin{array}{c}\text { Carbono, água, } \\
\text { biodiversidade, beleza } \\
\text { cênica }\end{array}$ & Conservação/Recuperação \\
\hline Vittel & França & Água & $\begin{array}{l}\text { Conservação/Recuperação } \\
\text { (práticas agrícolas) }\end{array}$ \\
\hline
\end{tabular}

No Brasil, tais iniciativas concentram-se principalmente no Sul e Sudeste do país, sendo a região Nordeste e os estados do Centro-Oeste, parcialmente abrangidos pela Mata Atlântica, são sub-representados: como exemplo, no caso do carbono e da água, a maioria dos projetos está localizada no estado de São Paulo, Minas Gerais e Espírito Santo (Guedes \& Seehusen, 2011).

O pioneirismo em relação ao PSA no país coube ao município de Extrema/MG, que em agosto de 2007 oficializou, a partir de uma lei municipal de 2005, o projeto "Conservador das Águas", com o objetivo de fomentar a preservação de mananciais e nascentes, localizado na microbacia das Posses, cabendo aos envolvidos a recuperação e a preservação das Áreas de Proteção Permanente e Reserva Legal, bem como a reconstituição da vegetação local, a proteção dos mananciais, o saneamento ambiental e a conservação do solo (Bernardes \& Junior, 2010). Esse projeto está inserido dentro do "Produtor de Água" da Agência Nacional de Águas (ANA). Além da parceria Prefeitura e ANA, este projeto conta com a participação de instituições, tais como o Instituto Estadual de Florestas (IEF), os Comitês das Bacias Hidrográficas dos Rios Piracicaba, Capivari e Jundiaí (Comitês PCJ) e The Nature Conservancy (TNC), que possuem, dentre outras funções fornecer suporte financeiro e técnico, monitoramento e mapeamento da área. Até 2009, os resultados deste programa de PSA resultaram na participação de 60 proprietários de terra, em um total de 1.393,49 ha beneficiados (Bernardes \& Junior, 2010).

Em Minas Gerais, o programa Bolsa Verde, foi instituído pela Lei Estadual n ${ }^{\circ} 17.727 / 2008$, e regulamentada pelo Decreto Estadual $n^{\circ} 45.113 / 2009$, com o objetivo de apoiar a conservação da cobertura vegetal nativa do estado (Minas Gerais, 2008). O programa tem preferência por pequenos produtores e proprietários que se localizam no interior de unidades de conservação e sujeitos à desapropriação, que devem se comprometer a recuperar e/ou preservar a vegetação nativa em suas propriedades ou posses. Espera-se que o Bolsa Verde se consolide em todo território mineiro, de forma permanente e universal, sendo acessível a todos os proprietários interessados a se vincular ao programa de acordo com os termos da legislação (IEF, 2012).

O PSA pode não ser uma iniciativa de órgãos públicos e envolver empresas privadas. Em 2006, após quase três anos de estudo, foi lançado em São Paulo o "Projeto Oásis" da Fundação Grupo Boticário, cujo objetivo principal era o de proteger mananciais na região de metropolitana de São Paulo e estimular a replicação deste mecanismo (Atanazio, 2011). Em 2009, o projeto chegou ao sul do país, em Apucarana (PR), em parceria com a Secretaria de Meio Ambiente e 
Turismo; em 2011, foi a vez de a cidade de São Bento do Sul (SC); e, em 2012, em parceria com o Ministério Público de Minas Gerais e a Associação Mineira de Defesa Ambiental (AMDA), iniciouse em Brumadinho (Fundação Grupo Boticário, 2014).

Há também, projetos baseados em ações voluntárias, ou seja, são feitos acordos entre quem paga e quem recebe pelo PSA. É o que acontece no litoral Sul na Bahia, no projeto "Turismo Carbono Neutro", realizado pela Associação Movimento Mecenas da Vida. O projeto, apoiado por estabelecimentos, objetiva reduzir e neutralizar as emissões de carbono, a conservação da biodiversidade e o desenvolvimento de comunidades localizadas na Área de Preservação Permanente Itacaré/Serra Grande (Cílios do Ribeira, 2014).

Além destas iniciativas, é pertinente a criação de uma política nacional de PSA que, apesar de requerer qualificações importantes, é plena de oportunidades que, se bem aproveitadas, poderão constituir em um instrumento estruturante de uma estratégia real de desenvolvimento sustentável (Shiki \& Shiki, 2011). Neste sentido, encontra-se em tramitação na Câmara dos Deputados o Projeto de Lei PL 792/2007, criado pelo Deputado Anselmo de Jesus, que dispõe sobre a Política Nacional de Pagamentos por Serviços Ambientais, cria o Programa Federal de Pagamento por Serviços Ambientais, estabelece formas de controle e financiamento deste Programa e dá outras providências (Câmara dos Deputados, 2007).

\section{METODOLOGIA}

\section{1 Área de estudo}

Para o desenvolvimento desta pesquisa foi escolhido o município mineiro de Monte Alegre de Minas, localizado na Mesorregião do Triângulo Mineiro e Alto Paranaíba, mas especificamente na microrregião de Uberlândia. Sua população é estimada em 19.619 habitantes, sendo que 26\% da população vive na zona rural (Instituto Brasileiro de Geografia e Estatística [IBGE], 2010). Seu território pertence à Bacia Hidrográfica do rio Paranaíba e abriga os biomas de cerrado e mata atlântica. A economia é baseada na agropecuária, tendo como principais produtos abacaxi, soja, laranja, cana, pecuária de leite e corte.

\subsection{Diagnóstico socioambiental dos potenciais provedores}

Segundo dados disponibilizados pela Prefeitura Municipal de Monte Alegre de Minas, o número total de propriedades rurais do município no ano de 2013 era de 2.415 . O cálculo da amostra de proprietários foi realizado com base em Santos (2014), utilizando um nível de confiança de $90 \%$ e um erro amostral de $12 \%$. Os valores do nível de confiança e do erro amostral foram adotados levando em consideração que o trabalho foi apenas exploratório. Assim, o diagnóstico socioambiental dos potenciais provedores de serviços ambientais foi baseado na aplicação de um questionário a 50 proprietários rurais da cidade de Monte Alegre. Este questionário possuía 20 questões e visou obter informações econômicas e sociais destes proprietários (características da propriedade, renda, atividades desenvolvidas, escolaridade, legalidade, entre outros), sua percepção ambiental da região e seu conhecimento e disponibilidade em participar de programas de PSA. Os produtores rurais foram selecionados de modo aleatório com base na relação de produtores apresentada pela Prefeitura Municipal de Monte Alegre de Minas, sendo abordados em sua residência. 


\subsection{Identificação dos potenciais pagadores}

Inicialmente, foi feito um levantamento dos atores envolvidos com questões ambientais na microrregião de Uberlândia e que poderiam envolver-se com programas de PSA, sendo órgãos municipais ou estaduais, organizações não governamentais (ONG) e, até mesmo, instituições privadas. A partir deste levantamento, foram selecionados cinco atores principais com os quais foram realizadas as entrevistas: Empresa de Assistência Técnica e Extensão Rural do Estado de Minas Gerais (EMATER) - sede de Monte Alegre de Minas; Instituto Estadual de Florestas (IEF); Comitê da Bacia Hidrográfica dos Afluentes Mineiros do Baixo Paranaíba - CBH-PN3; Prefeitura Municipal de Monte Alegre de Minas; e PCH-Piedade - Piedade Usina Geradora de Energia S/A. O objetivo das entrevistas (semiestruturada) foi de verificar se estes atores têm conhecimento sobre o potencial do instrumento PSA, se já existem iniciativas de PSA na região e qual a posição deles diante a possibilidade de implantação de um programa de PSA para atender o município de Monte Alegre de Minas e arredores.

Vale destacar que tanto o questionário como o roteiro da entrevista semiestruturada foram aprovados pelo Comitê de Ética em Pesquisas com Seres Humanos da Universidade Federal de Uberlândia (CAAE: 27860114.0.0000.5152, parecer no 750.504 de 11/07/2014).

\subsection{Análise SWOT}

A partir dos resultados da aplicação dos questionários e da realização das entrevistas foi realizada uma análise SWOT (Strengths, Weaknesses, Opportunities and Threats), também conhecida como FOFA, para a identificação das potencialidades, fraquezas, oportunidades e ameaças para a implantação de um sistema de PSA na microrregião de Uberlândia, mais especificamente no município de Monte Alegre de Minas.

\section{RESULTADOS E DISCUSSÃO}

\subsection{Diagnóstico socioambiental dos potenciais provedores}

Os resultados apresentados baseiam-se na aplicação do questionário a 50 proprietários rurais da cidade de Monte Alegre de Minas. Na região, predominam pequenas propriedades: $70 \%$ dos entrevistados possuem minifúndios, ou seja, propriedades menores que 4 módulos fiscais (o módulo fiscal no município de Monte Alegre equivale a 20 ha, logo, estas propriedades são menos que 80 ha). A grande maioria dos entrevistados, cerca de $80 \%$, reside na propriedade a mais de 10 anos e possuem mais de uma fonte de renda, entre as quais estão a agricultura familiar, a pecuária de corte e a pecuária de leite. Tais atividades, principalmente a pecuária de leite, são remuneradas mensalmente, sendo que aproximadamente $60 \%$ dos entrevistados possuem renda fixa. $O$ valor da renda mensal dos entrevistados é apresentado na Figura 2, onde $80 \%$ dos proprietários rurais possuem renda mensal menor que $\mathrm{R} \$ 3.000$. Mesmo com uma renda relativamente baixa, cerca de $70 \%$ dos entrevistados responderam que mais de seis pessoas vivem dela. 


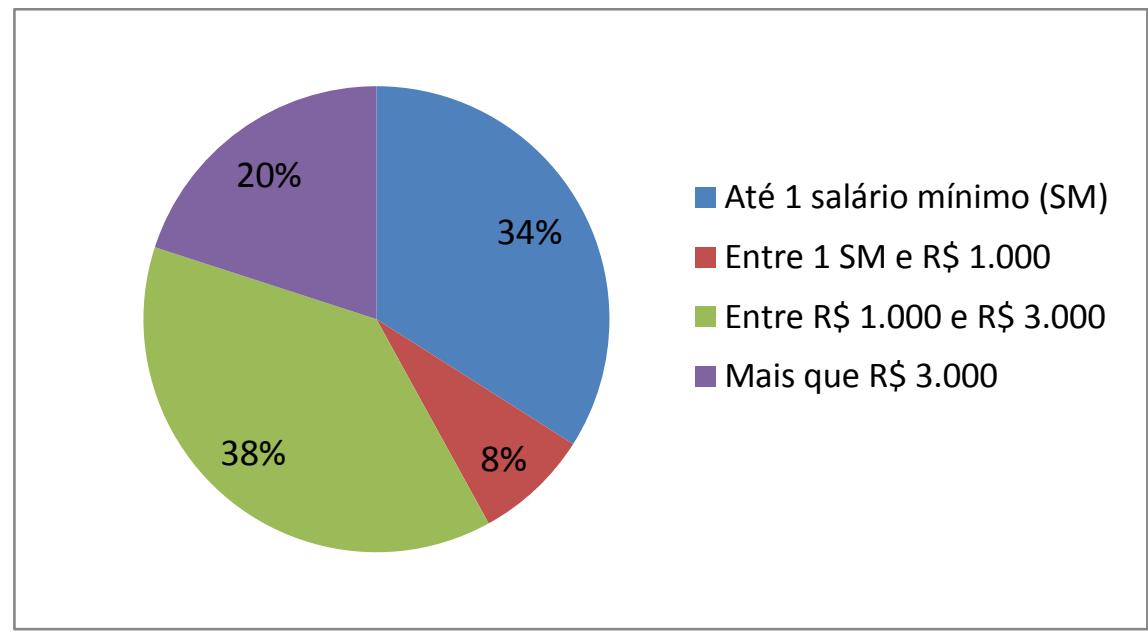

Figura 1: Renda mensal dos entrevistados.

Todos os entrevistados disseram serem proprietários das terras onde residem. Isso facilita a adesão aos projetos de PSA, visto que serão os próprios donos das terras que negociarão as diretrizes do projeto.

Nenhum dos entrevistados recebe qualquer tipo de incentivo ou benefício do governo. A respeito de incentivos do governo para preservar o ambiente, apenas um dos entrevistados já recebeu auxílio do programa Bolsa Verde. Tal produtor aderiu ao projeto e recebeu o benefício durante alguns meses, mas o programa parou de funcionar na região pouco tempo após sua implantação.

Em relação à percepção ambiental, $100 \%$ dos proprietários entrevistados observaram mudanças que indicam degradação do meio ambiente nos últimos anos. Dentre as mudanças citadas, as mais observadas foram a redução na quantidade e a alteração na qualidade da água e a alteração nos regimes de chuva. Assim, percebeu-se que na visão dos proprietários os maiores problemas estão relacionados aos recursos hídricos. Em relação à preservação ambiental, $86 \%$ dos entrevistados disseram possuir reserva legal na propriedade, sendo que destes $86 \%, 40 \%$ já estão averbadas. Além disso, cerca de $90 \%$ dos entrevistados afirmam preservar as Áreas de Preservação Permanente da propriedade. Esse alto valor deve-se à preocupação dos proprietários rurais em preservar os recursos hídricos, sendo um fator positivo para a implantação de programas de PSA no município.

Metade dos entrevistados não possui o costume de procurar qualquer tipo de órgão ambiental. A outra metade, quando precisaram, recorreram principalmente ao Instituto Estadual de Florestas (IEF), a Empresa de Assistência Técnica e Extensão Rural (EMATER), ou ao Instituto Brasileiro do Meio Ambiente e dos Recursos Naturais Renováveis (IBAMA).

Cerca de $70 \%$ dos entrevistados desconheciam o que era e iniciativas deste tipo de programa na região. Após a explicação do funcionamento deste instrumento pelo entrevistador, praticamente a totalidade dos proprietários rurais mostraram interesse em participar, caso algum projeto fosse implantado na região. Apenas um fazendeiro, proprietário de grande quantidade de terras na região, se recusou a responder. Sua justificativa foi que precisaria de mais informações sobre o assunto, e que esses projetos não costumam obter sucesso, além de que o valor pago é considerado por ele como insignificante. 
Quando se compara o perfil socioeconômico dos proprietários entrevistados com o perfil de proprietários que participam de programas de PSA já implantados (em especial o Produtor de Água de Extrema e o Projeto Oásis em uma parte do estado de São Paulo) percebem-se muitas semelhanças. Além disso, ficou muito claro, durante a aplicação dos questionários, o interesse por parte dos proprietários rurais em participar de projetos desta natureza.

A percepção ambiental dos proprietários entrevistados no que se diz respeito à água, sua qualidade e reconhecimento da sua importância e da necessidade de preservação, destaca a conservação de serviços hídricos como o tipo de PSA potencialmente mais aceito e adequado para a região.

\subsection{Identificação dos potenciais pagadores}

Conforme descrito na metodologia, foram entrevistados 5 atores envolvidos com a questão ambiental na microrregião de Uberlândia, focando a atuação destes atores no município de Monte Alegre de Minas.

O primeiro entrevistado foi um representante do IEF, órgão estadual que atua na promoção de ações para manutenção do equilíbrio ecológico, proteção da biodiversidade, educação ambiental, apoio ao reflorestamento e preservação ambiental. O IEF possui uma unidade no município de Monte Alegre de Minas desde 2004, tendo uma importante relação com o meio ambiente, por meio de ações na área florestal e no auxilio em algumas áreas relacionadas à fauna. No município, o IEF opera alguns programas relacionados à preservação do meio ambiente, como a conscientização dos proprietários rurais em relação à conservação ambiental, além de fazer parte do programa mineiro de PSA denominado Bolsa Verde. O entrevistado tinha conhecimento sobre o que era um programa de PSA, e mencionou um projeto de conservação das águas realizado pela prefeitura de Uberlândia. O IEF reconhece que a região possui grande potencial para a implantação de um programa deste, principalmente na parte de conservação das águas. Considerando o PSA uma iniciativa de grande importância, o órgão mostrou bastante interesse em participar de algum programa futuro, auxiliando no desenvolvimento do projeto. Apontou também as empresas privadas, a Prefeitura Municipal e impostos ecológicos como as principais fontes de recursos financeiros que poderiam ser destinados para a criação de um programa de PSA. Completou a entrevista ressaltando que ainda há poucas ações voltadas a preservação do meio ambiente, pois ainda falta iniciativa dos governos e empresas.

O segundo entrevistado foi um representante da Prefeitura Municipal, que trabalha como Diretor do Meio Ambiente. A relação da prefeitura com o meio ambiente é mantida por meio de: criação e manutenção de viveiro de mudas no município, incentivo ao reflorestamento e preservação ambiental e a supervisão do uso de defensivos agrícolas por parte dos produtores rurais, não tendo assim nenhum projeto em maior escala no presente e, por hora, nem planejamento para isso. O entrevistado desconhecia o significado de um programa de PSA e, consequentemente, não conhecia nenhum programa na região. Entretanto, achou a ideia do PSA uma iniciativa muito interessante e importante, acrescentando ainda que reconhecia um grande potencial na região para implementação de um programa de PSA voltado para preservação dos recursos hídricos. Isso se deve ao fato de que em maio de 2014 foi inaugurada uma estação de captação de água no Ribeirão da Babilônia, que fica próximo à cidade de Monte Alegre, com o objetivo de fornecer água potável aos moradores do município. A prefeitura reconheceu neste 
instrumento uma maneira de melhorar a qualidade da água fornecida a população, além de redução nos custos de seu tratamento. Assim, mostrou grande interesse em participar de um futuro projeto, e disse ainda que, com a parceria de empresas privadas, conseguiriam fontes de recursos que poderiam ser destinados para o programa.

O terceiro entrevistado foi um membro da EMATER, órgão responsável pelo atendimento principalmente ao pequeno produtor e a agricultura familiar, mas que pretende alcançar os grandes produtores no futuro. Possui uma unidade em Monte Alegre desde 1964, trabalhando com práticas sustentáveis, como assistência aos produtores de leite e ao uso correto de agrotóxicos, principalmente na plantação de abacaxi. No momento, a EMATER não possui nenhum programa direcionado a preservação ambiental, mas irá participar, juntamente com o Instituto Socioambiental do Cadastro Ambiental Rural, desenvolvendo mapas georreferenciados. O representante da EMATER desconhecia o significado de um programa de PSA e não conhecia nenhum programa relacionado na região. Todavia, achou a ideia muito interessante e importante, reconhecendo um grande potencial da região para a criação de um programa de PSA, principalmente relacionado à preservação dos recursos hídricos. Assim, a EMATER mostrou interesse em fazer parte de um futuro projeto de PSA, auxiliando na área de diagnósticos, visitas, divulgação e fornecimento de informações. Destacou ainda que a Prefeitura seria a principal fonte de recursos que poderiam ser destinados a um programa de PSA.

$\mathrm{O}$ quarto entrevistado foi um funcionário da PCH-Piedade - Piedade Usina Geradora de Energia S/A, empresa privada que atua na área de geração de energia em Monte Alegre desde 2010. Segundo ele, a empresa possui uma relação bastante harmônica com o meio ambiente, seguindo rigorosamente todos os seus deveres perante este. A PCH faz o monitoramento de espécies de pássaros da região, além de proteger a mata nativa no trecho de vazão reduzida do rio, sendo estas ações relacionadas ao monitoramento do seu processo de licenciamento. Mas além destas ações, não possui nenhum outro projeto relacionado a preservação do meio ambiente. O representante da usina desconhecia o significado de um programa de PSA, e também não conhecia nenhum projeto implantado na região. Apesar de achar uma iniciativa importante, não mostrou interesse em participar de um projeto de PSA, além de não saber de nenhuma fonte de recursos que poderiam ser destinados ao projeto.

O quinto e último entrevistado foi um membro do Comitê da Bacia Hidrográfica dos Afluentes Mineiros do Baixo Paranaíba - CBH-PN3, operando desde 30 de abril de 2004. Desde então, atua na área de recursos hídricos, na tomada de decisões de assuntos ligados a água com a participação das comunidades locais, faz negociações e tenta sempre resolver os problemas ambientais da bacia, além de ter caráter deliberativo e normativo das ações. 0 comitê foi criado com o intuito de preservar os recursos hídricos, assim, possui grande relação com a preservação do meio ambiente, como autorizações para outorgas e os impactos negativos e positivos que estas poderão causar no ambiente. O comitê apoia projetos que a ele são apresentados: anualmente, são abertas vagas para novos projetos, como recuperação de mata ciliar e recuperação de Área de Preservação Permanente, que, se aprovados pelo comitê, serão financiados por um fundo de recursos disponibilizado pelo governo. O membro do comitê conhecia o significado de um projeto de PSA e destacou os projetos de conservação das águas no sul de Minas Gerais (Extrema) e o Bolsa Verde. Reconheceu grande potencial de implantação de um programa de PSA na região, principalmente, os voltados para a preservação de nascentes. Ele considerou o PSA uma iniciativa muito importante e mostrou interesse em fazer parte de um possível projeto, com apoio na parte 
técnica. Complementou dizendo que parcerias com empresas privadas e com o governo seriam as possíveis fontes de recursos que poderiam ser destinados a um programa de PSA.

Por meio das entrevistas, foi observado um potencial favorável para a implementação de um programa de PSA na região, sendo que 4 dos 5 entrevistados se mostraram interessados em participar do programa. Destes que se interessaram, todos destacaram a conservação de serviços hídricos como a principal categoria a ser preservada na região. Isso pode ser explicado pelo fato de essa categoria ser a mais conhecida no Brasil, além de que nosso país possui uma grande quantidade de recursos hídricos. Outro fato que contribuiu para este destaque foi que recentemente inaugurou-se uma estação de captação e tratamento de água na cidade de Monte Alegre de Minas. Tal captação está sendo feita no Ribeirão da Babilônia, que passa pelo município e consequentemente por várias propriedades rurais. Assim, seguindo o modelo de outras ações, como o Conservador das Águas de Extrema/MG e o conservador das águas de Nova lorque nos Estados Unidos, é muito mais vantajoso ambientalmente e economicamente pagar para os proprietários preservarem os recursos hídricos e, assim, ter uma água limpa e de qualidade, do que fazer o posterior tratamento da água.

Vale destacar que a região do Triângulo Mineiro e, consequentemente, a cidade de Monte Alegre de Minas, está localizada em um ponto estratégico no país, podendo contribuir para a melhoria da qualidade e quantidade dos recursos hídricos, se programas de preservação ambiental forem implantados.

Analisando o Conservador das Águas de Extrema, é possível perceber que das instituições parceiras deste projeto, algumas coincidem com os atores que se mostraram interessados em participar do programa de PSA na região de Monte Alegre, que é a Prefeitura Municipal, o IEF e o Comitê de Bacias. Isso mostra que esses atores são parte importante para a criação e funcionamento de um programa de PSA. Essas parcerias são muito importantes para proporcionar ao projeto financiamentos, monitoramentos, apoio técnico e fornecimento de insumos, além de serem possíveis pagadores pelos serviços ambientais (JARDIM, 2010).

As fontes de recursos que poderiam ser destinados para um programa de PSA, segundo os entrevistados, seriam por parte de parcerias entre o governo, que no caso seria a Prefeitura, e empresas privadas. Mesmo a PCH Piedade não mostrando interesse em fazer parte de um projeto de PSA, outras empresas poderiam ser consultadas e demonstrar interesse em participar, usando esses projetos como um "marketing ambiental", adquirindo maior credibilidade para com os consumidores, além de contribuir para a preservação ambiental e preservar um recurso por eles utilizados em seu processo produtivo.

\subsection{Análise SWOT}

A partir dos resultados da aplicação do questionário aos proprietários rurais e da realização das entrevistas com os atores atuantes na questão ambiental no município de Monte Alegre de Minas foi realizada a análise SWOT, apresentada na Tabela 2.

Tabela 1: Resultados da análise SWOT

\begin{tabular}{c|c}
\hline Fatores Positivos & Fatores Negativos \\
\hline Potencialidades & Fraquezas \\
\hline
\end{tabular}




\begin{tabular}{|c|c|}
\hline $\begin{array}{l}\text { Melhoria da qualidade e quantidade da água; } \\
\text { Recuperação e/ou conservação de APP; } \\
\text { Grandes áreas preservadas; } \\
\text { Disponibilidade de recursos hídricos; } \\
\text { Predominância de propriedades pequenas; } \\
\text { Interesse dos proprietários; } \\
\text { Município pequeno (facilita a gestão); } \\
\text { Interesse da Prefeitura pelo projeto; } \\
\text { Possibilidade de apoio técnico (EMATER e IEF). }\end{array}$ & $\begin{array}{l}\text { Falta de informação a respeito deste tipo de } \\
\text { programa; } \\
\text { Falta de efetividade de alguns programas } \\
\text { implantados; } \\
\text { Não pagamento pelos serviços prestados; } \\
\text { Desconfiança dos proprietários rurais; } \\
\text { Desinteresse de empresas privadas; } \\
\text { Escassez de recursos financeiros. }\end{array}$ \\
\hline Oportunidades & Ameaças \\
\hline $\begin{array}{l}\text { Mercado dos serviços ambientais em ascensão; } \\
\text { Geração de renda para pequenos proprietários } \\
\text { rurais; } \\
\text { Novo local de captação de água na cidade de } \\
\text { Monte Alegre de Minas; } \\
\text { Exigência de adequação das propriedades rurais } \\
\text { à legislação; } \\
\text { Aprendizagem e troca de experiências entre os } \\
\text { profissionais envolvidos; } \\
\text { Aumento da consciência ambiental. }\end{array}$ & $\begin{array}{l}\text { Ausência de políticas públicas de incentivo; } \\
\text { Conhecimento limitado a respeito do PSA; } \\
\text { Falta de interesse político; } \\
\text { Ausência de uma política nacional de PSA. }\end{array}$ \\
\hline
\end{tabular}

\section{CONCLUSÃO}

Com o presente trabalho foi possível levantar informações sobre o município de Monte Alegre de Minas importantes para o delineamento e implantação de um programa de PSA. Diagnosticou-se o interesse dos proprietários rurais em prover os serviços ambientais de suas propriedades e o interesse de órgãos relacionados com a questão ambiental em participar deste tipo de programa, seja por meio de apoio financeiro ou técnico, com destaque para a Prefeitura Municipal.

A conservação de serviços hídricos mostrou-se como o tipo de PSA mais adequado para a microrregião. Além das características naturais, contribuiu para isto a inauguração de uma nova estação de captação na cidade. Nesse cenário, a implantação de um programa de PSA seria mais vantajosa, tanto econômica quanto ambientalmente, pois ao invés de se gastar para tratar uma água de baixa qualidade, se investiria e incentivaria a preservação e manutenção deste recurso.

Assim, conclui-se por um potencial favorável para implantar um programa de PSA em Monte Alegre de Minas, instrumento que, se bem elaborado e gerenciado, pode trazer benefícios ambientais e sociais, além de econômicos.

\section{REFERÊNCIAS}

Atanazio, R. (2011). Projeto Oásis: Pagamento por Serviços Ambientais. Recuperado em 05 novembro, 2014,

de http://www.prefeitura.sp.gov.br/cidade/secretarias/upload/meio_ambiente/arquivos/RPPN _projeto_oasis.pdf 
Bensusan, N. (2002). Seria melhor mandar ladrilhar: Biodiversidade como, para que, por que. Brasília: Instituto Socioambiental.

Bernardes, C., \& Junior, W. C. S. (2010). Pagamento por Serviços Ambientais: Experiências Brasileiras relacionadas à Água. V ENCONTRO NACIONAL DA ANPPAS. Florianópolis/PR. Recuperado em 05 novembro, 2014, de http://www.anppas.org.br/encontro5/cd/artigos/GT9-522-502-20100831170114.pdf

Britto, G. C., Kato, O. R., \& Herrera, J. A. (2012). A Prestação de Serviços Ambientais pode ser uma alternativa aos sistemas tradicionais da agricultura familiar no município de Pacajá, Amazônia Paraense - Brasil? Sustentabilidade em Debate. 3(2), 159-176.

Câmara dos Deputados. (2007). Projeto de Lei no 792 de 2007. Dispõe sobre a definição de serviços ambientais e dá outras providências. Recuperado em 05 de novembro, 2014, de http://www.camara.gov.br/proposicoesWeb/prop_imp;jsessionid=DE1171FB1FCE7CB4A975 AB9B0A0ABB02. node1 idProposicao $=348783 \&$ ord $=1 \&$ tp $=$ completa

Câmara dos Deputados. (2009). Projeto de Lei no 5.487 de 2009. Institui a Política Nacional dos Serviços Ambientais, o Programa Federal de Pagamento por Serviços Ambientais. Recuperado em 05 de novembro, 2014, de http://www.camara.gov.br/sileg/integras/667325.pdf

Cílios do Ribeira. (2011). Pagamentos por Serviços Ambientais. Recuperado em 05 de novembro, 2014, de http://www.ciliosdoribeira.org.br/pagamentos-por-servicos-ambientais

Claassen, R., Hansen, L., Peters, M., Breneman, V., Weinberg, M., Cattaneo, A., Feather, P., Gadsby, D., Hellerstein, D., Hopkins, J., Johnston, P., Morehart, M., \& Smith, M. (2001). Agrienvironmental policy at the crossroads: Guideposts on a changing landscape. USDA-ERS Report, n. 794.

Faganello, C. R. F. (2007). Fundamentação da cobrança pelo uso da água na agricultura irrigada, na microbacia do Ribeirão dos Marins, Piracicaba/SP. Tese de doutorado, Universidade de São Paulo, Piracicaba, SP, Brasil.

Forum Regional (2004). Payment schemes for environmental services in watersheds. Rome: FAO.

Fundação Grupo Boticário. (2014). Oásis. Recuperado em 05 de novembro, 2014, de http://www.fundacaogrupoboticario.org.br/pt/o-que-fazemos/oasis/pages/default.aspx

Guedes, F. B., \& Seehusen, S. E. (Org). (2011). Pagamentos por Serviços Ambientais na Mata Atlântica: Lições aprendidas e desafios. Brasília: Ministério do Meio Ambiente.

Gusmão, A. V. P. (2005). Problemas ambientais globais e a compensação por serviços ambientais como alternativa para a proteção do capital social e ecológico. Jus Navigandi. 9(589). Recuperado em 22 de abril, 2013, de http://jus.com.br/revista/texto/6341

Hupffer, H. M., Weyermüller, A. R., \& Waclawovsky, W. G. (2011). Uma análise sistêmica do princípio do protetor-recebedor na institucionalização de programas e compensação ambiental por serviços ambientais. Ambiente \& Sociedade. 14(1), 95-114.

IBGE - Instituto Brasileiro de Geografia e Estatística. (2010). IBGE Cidades. Recuperado em 25 abril, 
2013, de http://www.ibge.gov.br/cidadesat/painel/painel.php?codmun=314280\#

IEF - Instituto Estadual de Florestas. (2010). Bolsa verde: manual de princípios, critérios e procedimentos para a implantação da Lei n.o 17.727 de agosto de 2008. Belo Horizonte: Instituto Estadual de Florestas.

IEF - Instituto Estadual de Florestas. (2012). Bolsa Verde. Recuperado em 20 novembro, 2013, de http://www.ief.mg.gov.br/bolsa-verde

Jardim, M. H. (2010). Pagamentos por Serviços Ambientais na Gestão de Recursos Hídricos: o Caso do Município de Extrema-MG. Dissertação de mestrado, Universidade de Brasília, Brasília, DF, Brasil.

Jodas, N. (2010). Pagamento por Serviços Ambientais (PSA) como ferramenta efetiva à aplicabilidade do Código Florestal Brasileiro: uma proposta combativa ao Projeto de Lei no 1876/99. Relatos da experiência pioneira de PSA no município de Londrina - PR. Revista de Direito Público. 5(3), 66-80.

Kawaichi, V. M., \& Miranda, S. H. G. (2008). Políticas públicas ambientais: a experiência dos países no uso de instrumentos econômicos como incentivo à melhoria ambiental. XLVI Congresso da Sociedade Brasileira de Economia, Administração e Sociologia Rural. Rio Branco/AC.

King, N., letsaolo, A., \& Rapholo, B. (2003). Developing markets for watershed protection services and improved livehoods: a diagnostic for South Africa. London: International Institute for Environment and Development.

Landell Mills, N., \& PORRAS, I. (2002). Silver buller or fool's gold? A global review of markets for forest environmental services and their impact on the poor. IIED Catalogue.

Micol, L., Andrade, J., \& Borner, J. (2008). Redução das emissões do desmatamento e da degradação florestal (REDD): potencial de aplicação no Estado de Mato Grosso. Cuiabá: Instituto Socioambiental.

Millenium Ecosystem Assessment. (2005). Ecosystems and human well-being: Mountain Systems. Washington: Island Press and World Resources Institute. Recuperado em 05 de novembro, 2014, de http://www.fao.org/forestry/12480-0ace03c1c3b00d717817f18379f9414e.pdf

MINAM - Ministerio del Ambiente. (2010). Compensación por servicios ecosistémicos: Lecciones aprendidas de una experiência demonstrativa. Las microcuencas Mishiquiyacu, Rumiacu y Almendra de San Martín, Peru. Lima: Ministerio del Ambiente.

Minas Gerais. Lei no 17.727, de 13 de agosto de 2008 (2008). Dispõe sobre a concessão de incentivo financeiro a proprietários e posseiros rurais, sob a denominação de Bolsa Verde, para os fins que especifica, e altera as Leis no s 13.199, de 29 de janeiro de 1999, que dispõe sobre a Política Estadual de Recursos Hídricos, e 14.309, de 19 de junho de 2002, que dispõe sobre as políticas florestal e de proteção à biodiversidade no Estado. Belo Horizonte.

Lei n. 9.984, de 17 de julho de 2000 (2000). Dispõe sobre a criação da Agência Nacional de Águas ANA, entidade federal de implementação da Política Nacional de Recursos Hídricos e de 
coordenação do Sistema Nacional de Gerenciamento de Recursos Hídricos, e dá outras providências. Brasília. 2000. Recuperado em 10 abril, 2007, de http://www.planalto.gov.br/ccivil/Leis/L9984.htm

Moraes, J. L. A. (2012). Pagamento por Serviços Ambientais (PSA) como instrumento de Política de Desenvolvimento Sustentável dos Territórios Rurais: o projeto Protetor das águas de Vera Cruz, RS. Sustentabilidade em Debate. 3(1), 43-46.

Pagiola, S., Arcenas, A., \& Platais, G. (2005). Can Payments for Environmental Services Help Reduce Poverty? An Exploration of the Issues and the Evidence to Date from Latin America. World Development. 33(2), 237-253.

Pagiola, S., \& Platais, G. (2003). Pagos por servicios ambientales. Tercer Congreso Latinoamericana de Manejo de Cuencas Hidrográficas, Foro Regional sobre Sistemas de Pago por Servicios Ambientales. Arequipa, Peru.

Ribeiro, S. C., Chaves, H. M. L., Jacovine, L. A. G., \& Silva, M. L. (2007). Estimativa do abastecimento de erosão aportado por um sistema agrossilvipastoril e sua contribuição econômica. Revista Árvore. 31(2), 285-293.

Santos, P., Brito, B., Maschietto, F., Osório, G., \& Monzoni, M. (org.). (2012). Marco regulatório sobre pagamento por serviços ambientais no Brasil. Belém: IMAZON.

Santos, G. E. O. (2014). Cálculo amostral: calculadora on-line. Recuperado em 10 de fevereiro, 2014, de http://www.calculoamostral.vai.la

Seroa da Motta, R. (1998). Manual para valoração econômica dos recursos ambientais. Brasília: Ministério do Meio Ambiente.

Seroa Da Motta, R., Ruitenbeek, J., \& Huber, R. (1996). Uso de instrumentos econômicos na gestão ambiental da América Latina e Caribe: lições e recomendações. Rio de Janeiro: IPEA.

Shiki, S., \& Shiki, S. F. N. (2011). Os Desafios de uma Política Nacional de Pagamentos por Serviços Ambientais: lições a partir do caso do Proambiente. Sustentabilidade em Debate. 2(1), 99-118.

Silva, A., \& Joviano, P. E. A. (2012). Pagamento por Serviços Ambientais (PSA): princípio do protetor-recebedor. IX Congresso Brasileiro de Direito Constitucional e Cidadania. Londrina/PR.

Wunder, S., Börner, J., Tito, M. R., \& Pereira, L. (2009). Pagamentos por Serviços ambientais: perspectivas para a Amazônia legal. Brasília: Ministério do Meio Ambiente.

Young, R.A. (2005). Determining the economic value of water. Washington: RFF.

Zilberman, D., Lipper, L., \& Mccarthy, N. (2006). Putting payments for environment services in the context of economic development. Roma: ESA. 